\title{
Determination of Optimal Tilt Angle for Biannual Seasonally Adjusted Flat-Plate Photovoltaic Modules Based on Perez Transposition Model
}

\author{
Okon Dominic Ekanem, James O. Onojo \\ Department of Electrical/Electronic Engineering, Federal University of Technology Owerri (FUTO), Owerri, Nigeria
}

\section{Email address:}

engr.ekanem@yahoo.com (O. D. Ekanem)

\section{To cite this article:}

Okon Dominic Ekanem, James O. Onojo. Determination of Optimal Tilt Angle for Biannual Seasonally Adjusted Flat-Plate Photovoltaic Modules Based on Perez Transposition Model. American Journal of Software Engineering and Applications. Vol. 6, No. 3, 2017 , pp. 85-92. doi: 10.11648/j.ajsea.20170603.15

Received: January 3, 2017; Accepted: January 10, 2017; Published: June 12, 2017

\begin{abstract}
Determination of optimal tilt angle for seasonally adjusted flat-plate photovoltaic (PV) modules based on Perez transposition model is presented. Particularly, two seasons are considered, namely winter and summer. As such, two optimal tilt angles are obtained which requires that the tilt angle the of flat plate PV module will be adjusted twice in a year. The method is based on yearly global radiation incident on a horizontal plane as downloaded from NASA website. Furthermore, PVSyst software that uses transposition model is used to generate the yearly global radiation incident on a tilted plane for various tilt angles, from $0^{\circ}$ to $46^{\circ}$. The location used in the study is at longitude of 7.860761 , latitude of 5.011474 and elevation of $67.506 \mathrm{~m}$. The results show that the winter season optimal tilt angle is $25.46^{\circ}$ the summer season optimal tilt angle is $0^{\circ}$ and the yearly fixed optimal tilt angle is $7.16^{\circ}$. The annual transposition factor for the seasonally adjusted tilt angle is 1.05 whereas annual transposition factor for the year fixed tilt angle 1.01 . The result amounts to $3.6 \%$ improvement is solar radiation capture due to the seasonal adjustment of the tilt angle when compare to the yearly fixed tilt angle.
\end{abstract}

Keywords: Optimal Tilt Angle, Global Solar Radiation, PVSyst Software, Transposition Factor, Yearly Fixed Tile Angle, Seasonally Adjusted Tilt Angle

\section{Introduction}

In order to maximize solar energy collection photovoltaic (PV) modules are usually oriented toward the equator at optimal tilt-angle from the horizon [1-4]. The optimal tilt angle however varies with both time and location of the PV module [5-8]. In the simplest case, the yearly fixed optimal tilt angle is used. In other cases daily, monthly or seasonal adjustment of optimal tilt angle can be adopted. However, daily and monthly adjustment of tilt-angles is troublesome in practical application due to frequent adjustment and complex structure of frames which support solar panels. In this wise, seasonal adjustment of tilt-angle proves to be simpler and easier to be implemented in practice [1]. In particular, in Nigeria, as well as in PVSyst simulation software [9-13], two seasons are identified, namely; winter and summer. As such, winter and summer optimal tilt angles are to be determined and the PV module tilt angle need to be adjusted only two times in a year.

In any case, determination of the winter and summer optimal tilt angles requires transposition of the solar radiation on horizontal plane to that on the tilted plane. PVsyst software offers two transposition models, namely Hay's model and Perez model $[14,15]$. The two models differ by the way they determine the diffuse component of the radiation incident on a tilted plane. By default, the earlier versions of PVsyst software was using the Hay model. However, recent works of Pierre Ineichen [16-18] came to the conclusion that the Perez model is slightly better in any case, even with synthetic data. Therefore with the version 6 , the Perez model is proposed as default.

Specifically, in this paper, the Perez model is used in the PVSyst software to global radiation on the tilted plane for various tilt angles, from $0^{\circ}$ to $46^{\circ}$. For each month and for 
each of the tilt angles the transposition factor is determined. The Transposition Factor is the ratio of the incident irradiation on the titled plane, to the incident irradiation on horizontal plane [19-24]. Again, for each tilt angle, the average transposition factors for the winter and for the summer seasons are determined. Then, a quadratic trendline equation is fitted to the graph plot of average transposition factor versus the tilt angle for each of the two seasons. From the first derivative of the trendline equation, the optimal tilt angle is obtained [25-27]. This procedure is conducted separately for the winter season and for the summer season. Finally, the solar energy collected by the photovoltaic modules when the tilt angle is seasonally is compared with that obtained when the tilt angle is fixed at one value for the whole year. The aim is to ascertain the improvement in the solar radiation capture with the biannually adjusted tilt angle when compared to the yearly fixed tilt angle.

\section{Theoretical Background}

\subsection{Winter Season Optimal Tilt Angle}

With respect to the solar radiation pattern in Nigeria and also according to PVSyst software, two seasons are considered in this paper, namely; winter and summer. The winter season corresponds to the dry season in Nigeria and according to the PVSyst software winter season includes the months of October, November, December, January, February and March. On the other hand, the summer season corresponds to the rainy season in Nigeria and according to the PVSyst software includes the summer season the months of April, May, June,July, August and September.

Let $\mathrm{G}_{\mathrm{WH}}$ be the total of winter months global radiation on the horizontal plane and let $G_{\mathrm{WT}(\beta)}$ be the total of winter months global radiation on the titled plane at tilt angle $\beta$. Now, at tilt angle of zero, that is $\beta=0^{\circ}, G_{W H}=G_{W T(0)}$. $G_{W H}$ is obtained by adding the global radiation on the horizontal plane for the six months in winter, namely, October, November, December, January, February and March. Like wise $\mathrm{G}_{\mathrm{WT}(\beta)}$ is obtained by adding the global radiation on the tilted plane for the six months in winter. The winter transposition factor at tilt angle $\beta$ is denoted as $\mathrm{Tf}_{\mathrm{W}(\beta)}$ where;

$$
\operatorname{Tf}_{\mathrm{W}(\beta)}=\frac{G_{W T(\beta)}}{G_{W H}}=\frac{G_{W T(\beta)}}{G_{W T}(0)}
$$

The Perez transposition model is used in the PVSyst simulation software to generate the winter months' global radiation on the tilted plane, $\mathrm{G}_{\mathrm{WT}(\beta)}$ for various values of tilt angle $\beta$; where $\beta \geq 0$. Assuming the value of the $j$ th tilt angle is denoted as $\beta_{j}$ and a total of $\mathrm{n}$ tilt angles are considered, then the winter transposition factor at tilt angle $\beta_{j}$ is denoted as $\operatorname{Tf}_{\mathrm{W}\left(\beta_{j}\right)}$ where;

$$
\operatorname{Tf}_{\mathrm{W}\left(\beta_{j}\right)}=\frac{\mathrm{G}_{\mathrm{WT}\left(\beta_{j}\right)}}{G_{\mathrm{WH}}}=\frac{\mathrm{G}_{\mathrm{WT}\left(\beta_{j}\right)}}{G_{\mathrm{WT}(0)}} \text { for } j=0,1,2, \ldots \mathrm{n}-1
$$

The graph of $\mathrm{Tf}_{\mathrm{W}\left(\beta_{j}\right)}$ versus $\beta_{j}$ is plotted a quadratic trendline equation is fitted to the graph. The quadratic trendline equation is of the form:

$$
\mathrm{Tf}_{\mathrm{W}(\beta)}=\mathrm{A}(\beta)^{2}+\mathrm{D}(\beta)+\mathrm{E}
$$

In order to obtain the winter fixed optimal tilt angle, denoted as $\beta_{\text {Wopt }}$, the first derivative of the quadratic trendline equation is obtained as follows;

$$
\frac{\partial\left(\operatorname{Tf}_{\mathrm{W}(\beta)}\right)}{\partial(\beta)}=2(\mathrm{~A})(\beta)+\mathrm{D}
$$

By equating the $\frac{\partial\left(\mathrm{Tf}_{\mathrm{W}(\beta)}\right)}{\partial(\beta)}$ to zero and solving for $\beta$, the winter fixed optimal tilt angle, $\beta_{\text {Wopt }}$ is obtained as;

$$
\beta_{\mathrm{Wopt}}=\beta=\frac{-\mathrm{D}}{2(\mathrm{~A})}
$$

The winter optimal transposition factor is denoted as $\mathrm{Tf}_{\text {Wopt }}$, where;

$$
\mathrm{Tf}_{\mathrm{Wopt}}=\mathrm{A}\left(\beta_{\text {Yopt }}\right)^{2}+\mathrm{D}\left(\beta_{\text {Yopt }}\right)+\mathrm{E}
$$

\subsection{Summer Season Optimal Tilt Angle}

Let $\mathrm{G}_{\mathrm{SH}}$ be the total of the summer months global radiation on the horizontal plane and let $G_{\mathrm{ST}(\beta)}$ be the total of the summer months global radiation on the titled plane at tilt angle $\beta$. Now, at tilt angle of zero, that is $\beta=0^{\circ}, \mathrm{G}_{\mathrm{SH}}=\mathrm{G}_{\mathrm{ST}(0)}$. $\mathrm{G}_{\mathrm{SH}}$ is obtained by adding the global radiation on the horizontal plane for the six months in summer, namely, October, November, December, January, February and March. Like wise $\mathrm{G}_{\mathrm{ST}(\beta)}$ is obtained by adding the global radiation on the tilted plane for the six months in summer. The summer transposition factor at tilt angle $\beta$ is denoted as $\operatorname{Tf}_{\mathrm{S}(\beta)}$ where;

$$
\mathrm{Tf}_{\mathrm{S}(\beta)}=\frac{\mathrm{G}_{\mathrm{ST}(\beta)}}{\mathrm{G}_{\mathrm{SH}}}=\frac{\mathrm{G}_{\mathrm{ST}(\beta)}}{\mathrm{G}_{\mathrm{ST}(0)}}
$$

The Perez transposition model is used in the PVSyst simulation software to generate the total of the summer months' global radiation on the tilted plane, $\mathrm{G}_{\mathrm{ST}(\beta)}$ for various values of tilt angle $\beta$; for $\beta \geq 0$. Assuming the value of the jth tilt angle is denoted as $\beta_{j}$ and a total of $\mathrm{n}$ tilt angles are considered, then the summer transposition factor at tilt angle $\beta_{j}$ is denoted as $\operatorname{Tf}_{\mathrm{S}\left(\beta_{j}\right)}$ where;

$$
\operatorname{Tf}_{\mathrm{S}\left(\beta_{j}\right)}=\frac{\mathrm{G}_{\mathrm{ST}\left(\beta_{j}\right)}}{\mathrm{G}_{\mathrm{SH}}}=\frac{\mathrm{G}_{\mathrm{ST}\left(\beta_{j}\right)}}{\mathrm{G}_{\mathrm{ST}(0)}} \text { for } \mathrm{j}=0,1,2, \ldots \mathrm{n}-1
$$

The graph of $\operatorname{Tf}_{\mathrm{S}\left(\beta_{j}\right)}$ versus $\beta_{j}$ is plotted a quadratic trendline equation is fitted to the graph. The quadratic trendline equation is of the form:

$$
\mathrm{Tf}_{\mathrm{S}(\beta)}=\mathrm{A}(\beta)^{2}+\mathrm{D}(\beta)+\mathrm{E}
$$

In order to obtain the summer fixed optimal tilt angle, denoted as $\beta_{\text {Sopt }}$, the first derivative of the quadratic trendline equation is obtained as follows; 


$$
\frac{\partial\left(\mathrm{Tf}_{\mathrm{S}(\beta)}\right)}{\partial(\beta)}=2(\mathrm{~A})(\beta)+\mathrm{D}
$$

By equating the $\frac{\partial\left(\operatorname{Tf}_{\mathrm{S}(\beta)}\right)}{\partial(\beta)}$ to zero and solving for $\beta$, the summer fixed optimal tilt angle, $\beta_{\text {Sopt }}$ is obtained as;

$$
\beta_{\text {Sopt }}=\beta=\frac{-D}{2(A)}
$$

The summer optimal transposition factor is denoted as $\mathrm{Tf}_{\text {Sopt }}$, where;

$$
\mathrm{Tf}_{\text {Sopt }}=\mathrm{A}\left(\beta_{\text {Yopt }}\right)^{2}+\mathrm{D}\left(\beta_{\text {Yopt }}\right)+\mathrm{E}
$$

\subsection{Comparison of the Yearly Fixed and Seasonally Adjusted Optimal Tilt Angle for Flat-Plate PV Module}

The yearly fixed optimal tilt angle $\left(\beta_{\text {Yopt }}\right)$ for flat-plate photovoltaic (PV) module can be determined from the expression;

$$
\beta_{\text {Yopt }}=3.7+0.69|\varnothing|
$$

where $\varnothing$ is the latitude of the location.

PVSyst software is then used to determine $G_{\text {Yopt }}$ (that is the total yearly global radiation) on the titled plane at the yearly fixed optimal tilt angle ( $\left.\beta_{\text {Yopt }}\right)$. Also, the PVSyst software is used to determine $G_{\mathrm{WHopt}}$ (that is the total winter months' global radiation) on the titled plane at the winter optimal tilt angle $\left(\beta_{\text {Wopt }}\right)$. Again, the PVSyst software is used to determine $\mathrm{G}_{\text {SHopt }}$ (that is the total summer months' global radiation) on the titled plane at the summer optimal tilt angle $\left(\beta_{\text {Sopt }}\right)$. Let $\mathrm{G}_{\text {SAopt }}$ be the total yearly global radiation on the titled plane at the seasonally adjusted optimal tilt angles, $\beta_{\text {Wopt }}$ and $\beta_{\text {Sopt }}$. Hence,

$$
\mathrm{G}_{\text {SAopt }}=\mathrm{G}_{\text {WHopt }}+\mathrm{G}_{\text {SHopt }}
$$

The total yearly global radiation on the horizontal plane is the same in all cases. Let $\mathrm{G}_{\mathrm{YH}}$ be the total yearly global radiation on the horizontal plane. Then;

Let the yearly transposition factor at the yearly fixed optimal tilt angle $\left(\beta_{\text {Yopt }}\right)$ be denoted as $\mathrm{Tf}_{\mathrm{Y}(\beta \text { Yopt })}$ where;

$$
\begin{gathered}
\mathrm{Tf}_{\mathrm{Y}(\beta \text { Yopt })}=\frac{\mathrm{G}_{\mathrm{Yopt}}}{\mathrm{G}_{\mathrm{YH}}} \quad(14) \quad \beta_{\text {Wopt }}=\frac{-00.0066031}{2(-0.0001297)}=25.46^{\circ} \\
\mathrm{Tf}_{\text {Wopt }}=-0.0001297\left(\beta_{\text {Wopt }}\right)^{2}+0.0066031\left(\beta_{\text {Wopt }}\right)+1.00 \\
\mathrm{Tf}_{\text {Wopt }}=-0.0001297(9.71)^{2}+0.0066031(9.71)+1.00=1.0840
\end{gathered}
$$

Let the transposition factor at the seasonally adjusted optimal tilt angles ( $\beta_{\text {Wopt }}$ and $\beta_{\text {Sopt }}$. ) be denoted as $\mathrm{Tf}_{\mathrm{Y}(\beta S A o p t)}$ where;

$$
\mathrm{Tf}_{\mathrm{Y}(\beta S A o p t)}=\frac{\mathrm{G}_{\text {SAopt }}}{\mathrm{G}_{\mathrm{YH}}}
$$

The percentage in solar radiation gain $\left(\mathrm{P}_{\mathrm{SA}}\right)$ by the seasonally adjusted tilt angle is given as;

$$
\mathrm{P}_{\mathrm{SA}}=\left(\frac{\mathrm{G}_{\mathrm{SAopt}}-\mathrm{G}_{\mathrm{Yopt}}}{\mathrm{G}_{\mathrm{Yopt}}}\right) 100 \%
$$

\section{Simulation Process, Results and Discussions}

The location used in the study is at longitude of 7.860761 , latitude of 5.011474 and elevation of $67.506 \mathrm{~m}$. The data on global radiation incident on a horizontal plane is downloaded from NASA meteorology and solar energy website into PVSyst meteorological directory. The Perez transposition in PVSyst is then used to generate the global radiation incident on tilted plane for various tilt angles, from $0^{\circ}$ to $46^{\circ}$. Table 1 shows the total winter season global radiation incident on a horizontal, the total winter season global radiation incident on a tilted plane and the winter season transposition factor for various tilt angles. The total winter season global radiation is obtained by adding the values for each of the six winter months.

\subsection{Results for The Winter Season Optimal Tilt Angle}

Figure 1 shows the graph of winter season transposition factor, $\mathrm{Tf}_{\mathrm{W}(\beta)}$ versus tilt angle, $\boldsymbol{\beta}\left(^{\circ}\right)$. The quadratic trendline equation fitted onto the graph is given as;

$$
\begin{array}{r}
\mathrm{Tf}_{\mathrm{W}(\beta)}=-0.0001297 \beta^{2}+0.0066031 \beta+1.00 \\
\frac{\partial\left(\mathrm{Tf}_{\mathrm{W}(\beta)}\right)}{\partial(\beta)}=-0.0002594 \beta+00.0066031
\end{array}
$$

Equation 18 is the first derivative of Eq 17. The winter season optimal tilt angle is obtained from Eq 18 as follows; 
Table 1. The Winter Season Global Radiation Incident On A Horizontal, Winter Season Global Radiation Incident On A Tilted Plane and The Winter Season Transposition Factor For Various Tilt Angles.

\begin{tabular}{lllll}
\hline Tilt Angle $\left({ }^{\circ}\right)$ & $\begin{array}{l}\text { Total Of The Winter Season Global Radiation } \\
\text { Incident On A Horizontal Plane }\end{array}$ & $\begin{array}{l}\text { Total Of The Winter Season Global } \\
\text { Radiation Incident On A Tilted Plane }\end{array}$ & $\begin{array}{l}\text { Winter Season } \\
\text { Transposition Factor }\end{array}$ & $\begin{array}{l}\text { Tilt Angle } \\
\left({ }^{\circ}\right)\end{array}$ \\
\hline 0 & 992.1 & 992.1 & 1 & 24 \\
2 & 992.1 & 1004.505864 & 1.012505 & 1.023883 \\
4 & 992.1 & 1015.79424 & 1.034486 & 26 \\
6 & 992.1 & 1026.313957 & 1.044071 & 30 \\
8 & 992.1 & 1035.823277 & 1.052467 & 32 \\
10 & 992.1 & 1044.152283 & 1.059949 & 34 \\
12 & 992.1 & 1051.575106 & 1.066538 & 36 \\
14 & 992.1 & 1058.111968 & 1.072109 & 38 \\
16 & 992.1 & 1063.639531 & 1.076595 & 40 \\
18 & 992.1 & 1068.089895 & 1.079875 & 42 \\
20 & 992.1 & 1071.343999 & 1.08223 & 44 \\
22 & 992.1 & 1073.680665 & 46 \\
\hline
\end{tabular}

Table 1. Continue.

\begin{tabular}{llll}
\hline Tilt Angle $\left(^{\circ}\right)$ & $\begin{array}{l}\text { Total Of The Winter Season Global } \\
\text { Radiation Incident On A Horizontal Plane }\end{array}$ & $\begin{array}{l}\text { Total Of The Winter Season Global } \\
\text { Radiation Incident On A Tilted Plane }\end{array}$ & $\begin{array}{l}\text { Winter Season Transposition } \\
\text { Factor }\end{array}$ \\
\hline 0 & 992.1 & 1075.036 & 1.083596 \\
2 & 992.1 & 1075.192 & 1.083754 \\
4 & 992.1 & 1074.463 & 1.083018 \\
6 & 992.1 & 1072.532 & 1.081073 \\
8 & 992.1 & 1069.717 & 1.078236 \\
10 & 992.1 & 1065.889 & 1.074377 \\
12 & 992.1 & 1060.894 & 1.069341 \\
14 & 992.1 & 1054.996 & 1.063397 \\
16 & 992.1 & 1047.9 & 1.056244 \\
18 & 992.1 & 1039.915 & 1.048196 \\
20 & 992.1 & 1030.908 & 1.039117 \\
22 & 992.1 & 1020.839 & 1.028967 \\
\hline
\end{tabular}

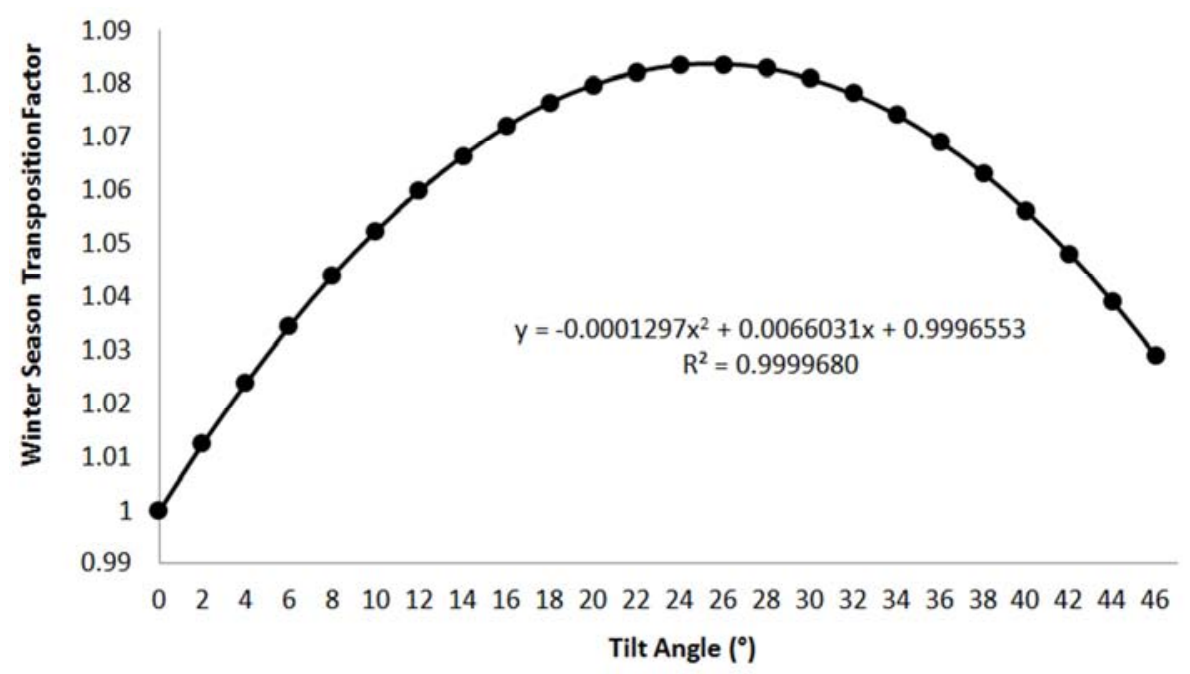

Figure 1. The Graph of Winter Season Transposition Factor, $T f_{W(\beta)}$ versus Tilt Angle, $\beta\left(^{\circ}\right)$.

\subsection{Results for The Summer Season Optimal Tilt Angle}

The location used in the study is at longitude of 7.860761 , latitude of 5.011474 and elevation of $67.506 \mathrm{~m}$. The data on global radiation incident on a horizontal plane is downloaded from NASA meteorology and solar energy website into PVSyst meteorological directory. The Perez transposition in PVSyst is then used to generate the global radiation incident on tilted plane for various tilt angles, from $0^{\circ}$ to $46^{\circ}$.

Table 2 shows the total summer season global radiation incident on a horizontal, the total summer season global radiation incident on a tilted plane and the summer season transposition factor for various tilt angles. The total summer season global radiation is obtained by adding the values for each of the six summer months. 
Table 2. The Summer Season Global Radiation Incident On A Horizontal, Season Months' Global Radiation Incident On A Tilted Plane and The Summer Season Transposition Factor For Various Tilt Angles.

\begin{tabular}{llll}
\hline Tilt Angle $\left({ }^{\circ}\right)$ & $\begin{array}{l}\text { Total Of The Summer Season Global Radiation } \\
\text { Incident On A Horizontal Plane }\end{array}$ & $\begin{array}{l}\text { Total Of The Summer Season Global } \\
\text { Radiation Incident On A Tilted Plane }\end{array}$ & $\begin{array}{l}\text { Summer Season } \\
\text { Transposition Factor }\end{array}$ \\
\hline 0 & 835.6 & 835.6 & 1 \\
2 & 835.6 & 830.6301 & 0.994052 \\
4 & 835.6 & 824.9927 & 0.987306 \\
6 & 835.6 & 818.5198 & 0.979559 \\
8 & 835.6 & 811.472 & 0.971125 \\
10 & 835.6 & 803.7158 & 0.961843 \\
12 & 835.6 & 795.0772 & 0.951505 \\
14 & 835.6 & 785.8181 & 0.940424 \\
16 & 835.6 & 776.0672 & 0.928754 \\
18 & 835.6 & 765.4338 & 0.916029 \\
20 & 835.6 & 754.3848 & 0.902806 \\
22 & 835.6 & 742.5681 & 0.888665 \\
\hline
\end{tabular}

Table 2. Continue.

\begin{tabular}{lllll}
\hline Tilt Angle $\left(^{\circ}\right)$ & Tilt Angle $\left.^{(}{ }^{\circ}\right)$ & $\begin{array}{l}\text { Total Of The Summer Season Global } \\
\text { Radiation Incident On A Horizontal Plane }\end{array}$ & $\begin{array}{l}\text { Total Of The Summer Season' Global } \\
\text { Radiation Incident On A Tilted Plane }\end{array}$ & $\begin{array}{l}\text { Summer Season } \\
\text { Transposition Factor }\end{array}$ \\
\hline 0 & 24 & 835.6 & 730.2212 & 0.873888 \\
2 & 26 & 835.6 & 717.1863 & 0.858289 \\
4 & 28 & 835.6 & 703.457 & 0.841859 \\
6 & 30 & 835.6 & 689.3371 & 0.824961 \\
8 & 32 & 835.6 & 674.6115 & 0.807338 \\
10 & 34 & 835.6 & 659.281 & 0.788991 \\
12 & 36 & 835.6 & 643.4476 & 0.770043 \\
14 & 38 & 835.6 & 627.7221 & 0.751223 \\
16 & 40 & 835.6 & 611.2053 & 0.731457 \\
18 & 42 & 835.6 & 594.2886 & 0.711212 \\
20 & 44 & 835.6 & 577.0795 & 0.690617 \\
22 & 46 & 835.6 & 559.3566 & 0.669407 \\
\hline
\end{tabular}

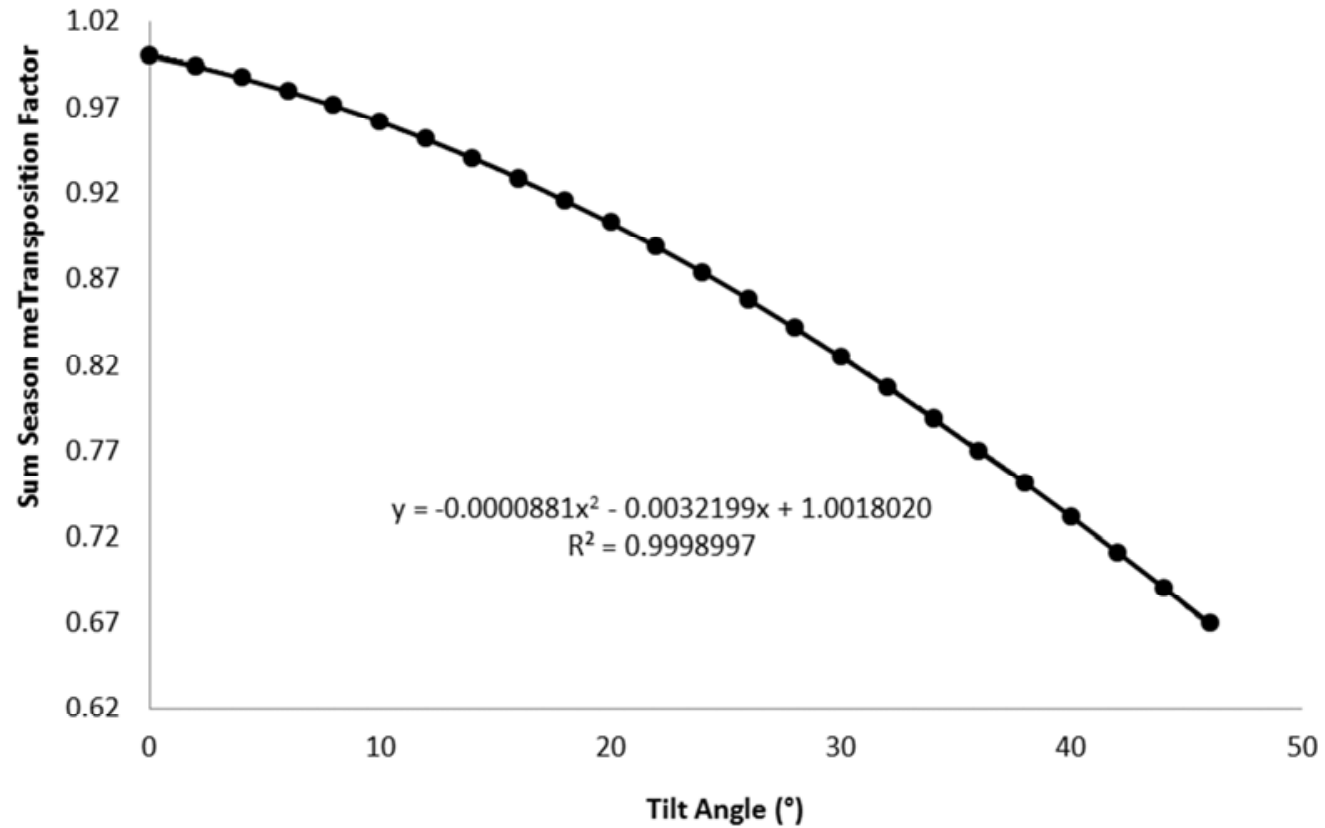

Figure 2. The Graph of Summer Season Transposition Factor, $T f_{S(\beta)}$ versus Tilt Angle, $\beta\left(^{\circ}\right)$.

Figure 2 shows the graph of summer season transposition factor, $\mathrm{Tf}_{\mathrm{S}(\beta)}$ versus tilt angle, $\beta\left(^{\circ}\right)$. The quadratic trendline equation fitted onto the graph is given as;

$$
\operatorname{Tf}_{\mathrm{S}(\beta)}=-0.0000881 \beta^{2}-0.0032199 \beta+1.00
$$




$$
\frac{\partial\left(\mathrm{Tf}_{\mathrm{S}(\beta)}\right)}{\partial(\beta)}=-0.0001762 \beta-0.0032199
$$

Equation 23 is the first derivative of Eq 22. The summer season optimal tilt angle is obtained from Eq 24 as follows;

$$
-0.0000881 \beta^{2}-0.0032199 \beta+1.00=1.00 \text { for } \beta=0
$$

And

$$
-0.0000881 \beta^{2}-0.0032199 \beta+1.00<1.00 \text { for all } \beta>0
$$

Therefore, maximum summer transposition factor occurs at $\beta=0$. This means that the effective summer fixed optimal tilt angle, $\beta_{\text {Sopt }}$ is obtained at $\beta=0$. Hence;

$$
\beta_{\text {Sopt }}=0
$$

The summer season optimal tilt angle is $0^{\circ}$ and from Eq 22 the summer season transposition factor (at $\beta=\beta_{\text {sopt }}=0$ ) is 1.

\subsection{Comparison of The Yearly Fixed and Seasonally Adjusted Optimal Tilt Angle for Flat-Plate PV Module}

Given that the latitude of the study location is 5.011474, then the optimal tilt angle for yearly fixed tilted PV module at the study location is obtained as;

$$
\beta_{\text {Yopt }}=3.7+0.69|5.011474|=7.16^{\circ}
$$

The NASA data for the total yearly global radiation incident

Table 3. The Winter Months' Global Radiation Incident On A Horizontal and The Winter Months' Global Radiation Incident On Optimal Tilted Plane.

\begin{tabular}{lll}
\hline Winter Months & $\begin{array}{l}\text { Global Radiation Incident On A Horizontal Plane } \mathbf{( k W h} / \mathbf{m}^{2} . \\
\text { mth) }\end{array}$ & $\begin{array}{l}\text { Global Radiation Incident On Optimal Tilted Plane } \\
\left(\mathbf{k W h} / \mathbf{m}^{2} . \mathbf{m t h}\right)\end{array}$ \\
\hline Jan & 180 & 206.7 \\
Feb & 172.6 & 185.5 \\
Mar0 & 175.9 & 171.7 \\
Oct & 135.6 & 137.9 \\
Nov & 153.4 & 171.1 \\
Dec & 174.6 & 204.6 \\
WINTER & 992.1 & 1077.5 \\
\hline
\end{tabular}

Table 4. The Summer Months' Global Radiation Incident On A Horizontal and The Summer Months' Global Radiation Incident On Optimal Tilted Plane.

\begin{tabular}{lll}
\hline Summer Months & $\begin{array}{l}\text { Global Radiation Incident On A Horizontal Plane } \\
\left(\mathbf{k W h} / \mathbf{m}^{\mathbf{2}} \mathbf{~ m t h}\right)\end{array}$ & $\begin{array}{l}\text { Global Radiation Incident On Optimal Tilted Plane } \\
\left(\mathbf{k W h} / \mathbf{m}^{2} \mathbf{m} \mathbf{~ m}\right)\end{array}$ \\
\hline Apr & 160.9 & 160.9 \\
May & 152.9 & 152.9 \\
Jun & 140.5 & 140.5 \\
Jul & 129 & 129 \\
Aug & 122.3 & 122.3 \\
Sep & 130 & 130 \\
Summer & 835.6 & 835.6 \\
\hline
\end{tabular}

Similarly, Table 4 shows the summer months' global radiation incident on a horizontal and the summer months' global radiation incident on optimal tilted plane. From Table 4 the total summer season global radiation incident on a horizontal is 835.6 $\mathrm{kWh} / \mathrm{m}^{2}$ while the total summer season global radiation incident on the winter season optimal tilt angle is $\mathrm{G}_{\mathrm{SHopt}}=835.6$ $\mathrm{kWh} / \mathrm{m}^{2}$. Hence,

$$
\mathrm{G}_{\text {SAopt }}=\mathrm{G}_{\mathrm{WHopt}}+\mathrm{G}_{\text {SHopt }}=1077.5+835.6=1913.1 \mathrm{kWh} / \mathrm{m}^{2} . \mathrm{yr}
$$


Then, the transposition factor for the seasonally adjusted optimal tilt angle is obtained as;

$$
\mathrm{Tf}_{\mathrm{Y}(\beta S A o p t)}=\frac{\mathrm{G}_{\text {SAopt }}}{\mathrm{G}_{\mathrm{YH}}}=\frac{1913.1}{1827.6}=1.05
$$

This means that compared with the PV module on horizontal plane, the seasonally adjusted optimal tilt angle will improve on the amount of solar radiation captured by the PV module by about 5\% (that is, $(1.05-1) 100 \%$ ). Again,

$$
\mathrm{P}_{\mathrm{SA}}=\left(\frac{\mathrm{G}_{\mathrm{SAopt}}-\mathrm{G}_{\mathrm{Yopt}}}{\mathrm{G}_{\mathrm{Yopt}}}\right) 100 \%=\left(\frac{1913.1-1827.6}{1827.6}\right) 100 \%=3.6 \%
$$

This means that compared with the PV module with yearly fixed optimal tilt angle, the seasonally adjusted optimal tilt angle will improve on the amount of solar radiation captured by the PV module by about $3.6 \%$.

\section{Conclusion}

A study on seasonally adjusted flat-plate PV module is presented. The focus is on the determination of the winter and summer seasons optimal tilt angle and the yearly transposition factor realized by adopting the two seasonal adjustment on the optimal tilt angle of the flat plate PV module. The results show significant improvement in solar radiation captured by the PV module when the seasonal adjustment is adopted.

The method for determining the optimal tilt angle for the yearly fixed at any given location is presented. A sample health facility in Uyo, Akwa Ibom state, Nigeria with longitude of 7.860761, latitude of 5.011474 and elevation of $67.506 \mathrm{~m}$ is used to demonstrate the applicability of the method. In all, the optimal tilt angle for the yearly fixed flat-plate PV module at the selected location is determined along with the average yearly transposition factor at the optimal tilt angle.

\section{References}

[1] Mohammadi, K., Mostafaeipour, A., \& Sabzpooshani, M. (2014). Assessment of solar and wind energy potentials for three free economic and industrial zones of Iran. Energy, 67, 117-128.

[2] Li, G. H., Tang, R. S., \& Zhong, H. (2015, July). Optical performance of horizontal single-axis tracked solar panels. In Specialized Collections (Vol. 2, pp. 3232-3237). Trans Tech Publications.

[3] Mageshwaran, G., Ramachandran, S., Gobinath, K., \& DuraiRaj, R. B. (2016). Design of tracking system for helical-coiled receiver tube of parabolic trough collector. International Journal of Ambient Energy, 1-5.

[4] Y. M. Chen, C. H. Lee, H. C. Wu, (2005)“Calculation of optimum installation angle for fixed solar-cell panels based on the genetic algorithm and the simulated annealing method," IEEE Transaction on Energy Conversion 20/2, pp.467-473, 2005.

[5] Mondol, J. D., Yohanis, Y. G., \& Norton, B. (2007). The impact of array inclination and orientation on the performance of a grid-connected photovoltaic system. Renewable Energy, 32 (1), 118-140.
[6] Darhmaoui, H., \& Lahjouji, D. (2013). Latitude based model for tilt angle optimization for solar collectors in the Mediterranean Region. Energy Procedia, 42, 426-435.

[7] Rakovec, J., Kastelec, D., Zakšek, K., Brecl, K., \& Marko Topic. (2011). Orientation and Tilt Dependence of a Fixed PV Array Energy Yield Based on Measurements of Solar Energy and Ground Albedo-a Case Study of Slovenia. INTECH Open Access Publisher.

[8] Kurnik, J., Jankovec, M., Brecl, K., \& Topič, M. (2008). Development of outdoor photovoltaic module monitoring system. Informacije MIDEM, 38 (2), 75-80.

[9] Tallab, R., \& Malek, A. (2015, December). Predict system efficiency of $1 \mathrm{MWc}$ photovoltaic power plant interconnected to the distribution network using PVSYST software. In 2015 3rd International Renewable and Sustainable Energy Conference (IRSEC) (pp. 1-4). IEEE.

[10] Badri, A., Emadifar, R., \& Eldoromi, M. (2016). Simulation and evaluation of solar potential in Tehran, Kerman and Yazd for a $500 \mathrm{~kW}$ photovoltaic power plant using PVsyst software. Iranian Journal of Energy, 19 (1), 0-0.

[11] Witzig, A., Prandini, M., Wolf, A., \& Kunath, L. (2016). Teaching Renewable Energy Systems by Use of Simulation Software: Experience at Universities of Applied Sciences, in In-Service Training, and from International Know-How Transfer. Presented at and in the proceedings of Eurosun, 2016, 13.

[12] Okello, D., van Dyk, E. E., \& Vorster, F. J. (2015). Analysis of measured and simulated performance data of a $3.2 \mathrm{kWp}$ grid-connected PV system in Port Elizabeth, South Africa. Energy Conversion and Management, 100, 10-15.

[13] Rachchh, R., Kumar, M., \& Tripathi, B. (2016). Solar photovoltaic system design optimization by shading analysis to maximize energy generation from limited urban area. Energy Conversion and Management, 115, 244-252.

[14] Mitra, I., Davis, M., \& Pasicko, R. (2011). MS32, MS34.

[15] Burgess, P. A., Vahdati, M. M., Davies, D. D., \& Philip, S. K. Development Of A Virtual Pyranometer For Solar Energy Monitoring. TSBE EngD Conference, TSBE Centre, University of Reading, Whiteknights, RG6 6AF, 5th July 2011. Available at: http://www.reading.ac.uk/web/files/tsbe/burgess_tsbe_conf_2 011.pdf. Accessed on December $24^{\text {th }} 2016$.

[16] Handoyo, E. A., \& Ichsani, D. (2013). The optimal tilt angle of a solar collector. Energy Procedia, 32, 166-175.

[17] Mehleri, E. D., Zervas, P. L., Sarimveis, H., Palyvos, J. A., \& Markatos, N. C. (2010). Determination of the optimal tilt angle and orientation for solar photovoltaic arrays. Renewable Energy, 35(11), 2468-2475.9]. 
[18] Kaddoura, T. O., Ramli, M. A., \& Al-Turki, Y. A. (2016). On the estimation of the optimum tilt angle of PV panel in Saudi Arabia. Renewable and Sustainable Energy Reviews, 65, 626-634.

[19] Yu, D., Gudmundsdottir, R., Catteau, R., Kamel, R., Fung, A., Mohammadi, F., \& Raahemifar, K. VALIDATING A SIMPLIFIED PV MODEL AGAINST TRNSYS MODEL.

[20] Gueymard, C. A. (2008). From Global Horizontal to Global tilted irradiance: how accurate are solar energy engineering predictions in practice. In Solar 2008 Conf., San Diego, CA, American Solar Energy Society.

[21] Al-Mimar, S. (2015). Integration of solar and wind power at Lillgrundwind farm.: Wind turbine shadow effect on solar farm atLillgrund wind farm.

[22] Georgitsioti, T. (2015). Photovoltaic potential and performance evaluation studies in India and the UK (Doctoral dissertation, Northumbria University).
[23] Failla, M. C. (2016). Snow and Ice on Photovoltaic Devices-Analysis of a Challenge and Proposals for Solutions (Master's thesis, NTNU).

[24] Mermoud, A., \& Wittmer, B. (2014). PVSYST user's manual. Switzerland, January.

[25] Lan, H., Dai, J., Wen, S., Hong, Y. Y., Yu, D. C., \& Bai, Y. (2015). Optimal Tilt Angle of Photovoltaic Arrays and Economic Allocation of Energy Storage System on Large Oil Tanker Ship. Energies, 8(10), 11515-11530.

[26] Karafil, A., Ozbay, H., Kesler, M., \& Parmaksiz, H. (2015, November). Calculation of optimum fixed tilt angle of PV panels depending on solar angles and comparison of the results with experimental study conducted in summer in Bilecik, Turkey. In 2015 9th International Conference on Electrical and Electronics Engineering (ELECO) (pp. 971-976). IEEE.

[27] Handoyo, E. A., \& Ichsani, D. (2013). The optimal tilt angle of a solar collector. Energy Procedia, 32, 166-175. 